\title{
Trait structure and redundancy determine sensitivity to disturbance in marine fish communities
}

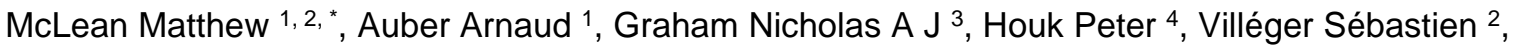 \\ Violle Cyrille ${ }^{5}$, Thuiller Wilfried ${ }^{6}$, Wilson Shaun K. ${ }^{7,8}$, Mouillot David ${ }^{2,9}$
}

1 IFREMER Unité Halieutique de Manche et mer du Nord 62321 Boulogne-sur-Mer, France

2 MARBEC Université de Montpellier CNRS IFREMER IRD 34095 Montpellier Cedex, France

3 Lancaster Environment Centre Lancaster University LancasterLA1 4YQ, UK

4 UOG Station University of Guam Marine Laboratory Mangilao Guam 96923, USA

${ }^{5}$ Centre d'Ecologie Fonctionnelle et Evolutive (CEFE) Unité Mixte de Recherche (UMR) 5175 Centre

National de la Recherche Scientifique (CNRS) Université de Montpellier Université Paul-Valéry

Montpellier Ecole Pratique des Hautes Etudes (EPHE) Montpellier ,France

6 Univ. Grenoble Alpes CNRS Univ. Savoie Mont Blanc Laboratoire d'Ecologie Alpine (LECA) F-38000

Grenoble, France

7 Department of Parks and Wildlife Kensington, Perth Western Australia 6151, Australia

8 Oceans Institute University of Western Australia Crawley Western Australia 6009, Australia

${ }_{9}^{9}$ Australian Research Council Centre of Excellence for Coral Reef Studies James Cook University

Townsville QLD 4811, Australia

*Corresponding author : Matthew McLean, email address : mcleamj@gmail.com

\begin{abstract}
:
'Functional' diversity is believed to influence ecosystem dynamics through links between organismal traits and ecosystem processes. Theory predicts that key traits and high trait redundancy - large species richness and abundance supporting the same traits - can buffer communities against environmental disturbances. While experiments and data from simple ecological systems lend support, large-scale evidence from diverse, natural systems under major disturbance is lacking. Here, using long-term data from both temperate (English Channel) and tropical (Seychelles Islands) fishes, we show that sensitivity to disturbance depends on communities' initial trait structure and initial trait redundancy. In both ecosystems, we found that increasing dominance by climatically-vulnerable traits rendered fish communities more sensitive to environmental change, while communities with higher trait redundancy were more resistant. To our knowledge, this is the first study demonstrating the influence of trait structure and redundancy on community sensitivity over large temporal and spatial scales in natural systems. Our results exemplify a consistent link between biological structure and community sensitivity that may be transferable across ecosystems and taxa and could help anticipate future disturbance impacts on biodiversity and ecosystem functioning.
\end{abstract}

Keywords : climate change, coral reefs, diversity-stability, ecological traits, ecosystem functioning, English Channel, functional diversity 


\section{Introduction}

Global environmental changes are threatening the sustainability of ecosystem functions and services, with severe consequences for human livelihood and wellbeing (Bellard, Bertelsmeier, Leadley, Thuiller, \& Courchamp, 2012; Cheung, Reygondeau, \& Frölicher, 2016; Mora et al., 2015; Smith \& Myers, 2018). It is therefore crucial to understand how variation in biodiversity may influence the sensitivity of communities and ecosystems to

This article is protected by copyright. All rights reserved. 
environmental change (Beaugrand, Edwards, Raybaud, Goberville, \& Kirby, 2015; Heilpern, Weeks, \& Naeem, 2018; Nolan et al., 2018; Segan, Murray, \& Watson, 2016). Species diversity has been shown to sustain ecosystem productivity and stability under environmental disturbances (Isbell et al., 2015; Liu et al., 2018; Mellin, Bradshaw, Fordham, \& Caley, 2014; Schneider, Brose, Rall, \& Guill, 2016). However, beyond species diversity, examining the diversity of organismal traits can provide a more mechanistic understanding of community dynamics via trait-environment relationships and through associated changes in ecosystem processes (Cadotte, 2017; Craven et al., 2018; Gross et al., 2017; Sakschewski et al., 2016).

Under the insurance (or redundancy) hypothesis, several species supporting similar key ecological roles, (i.e., sharing similar ecological traits), should buffer communities against the impacts of environmental change (Dee et al., 2016; Díaz \& Cabido, 2001; Laliberté et al., 2010; Nash, Graham, Jennings, Wilson, \& Bellwood, 2016; Sanders, Thébault, Kehoe, \& van Veen, 2018). Limited experimental and observational evidence over small temporal and spatial scales support this theory. For instance, on coral reefs, key functions such as grazing and bio-erosion by large parrotfishes can maintain benthic community resilience following disturbances (Bozec, O’Farrell, Bruggemann, Luckhurst, \& Mumby, 2016; Heenan, Hoey, Williams, \& Williams, 2016; McLean, Cuetos-Bueno, Nedlic, Luckymiss, \& Houk, 2016), and redundancy within parrotfish groups may reinforce these functions (Burkepile \& Hay, 2008). In plant communities, higher trait redundancy has been linked to higher community stability in experimental plots exposed to grazing (Pillar et al., 2013). However, long-term empirical evidence demonstrating the buffering effects of trait redundancy in ecological communities is lacking.

The insurance hypothesis additionally suggests that community dynamics depend not only on environmental variation but also on the initial biological structure of communities. Indeed, the initial structure of communities can determine their successional trajectories 
under disturbance (Fukami, Martijn, Mortimer, \& Putten, 2005; Williams et al., 2010), and two potential (non-mutually exclusive) biological mechanisms may explain differences in sensitivity among communities impacted by similar disturbances: 1) sensitive communities are more dominated by species with vulnerable traits (to a given disturbance), and/or 2) sensitive communities have lower trait redundancy (Walker, 1992; Williams et al., 2010). Thus communities' initial trait structure at a baseline time period (i.e., pre-disturbance) could determine communities' sensitivity or resistance to environmental disturbances (Barros, Thuiller, Georges, Boulangeat, \& Münkemüller, 2016). However, while limited evidence supports the insurance hypothesis, no study has examined whether key traits or initial trait redundancy can buffer communities against environmental change in natural systems across large temporal and spatial scales.

Here, using multidimensional spaces based on species' ecological traits, we assessed whether community sensitivity was determined by initial trait structure or initial trait redundancy. Using long-term data from both temperate and tropical marine fish communities, we show that increased dominance by species with climatically-vulnerable traits rendered communities more susceptible to environmental change, while communities with higher trait redundancy were more resistant, demonstrating the potential buffering capacity of trait redundancy in diverse, natural systems.

This article is protected by copyright. All rights reserved. 


\section{Materials and Methods}

\section{Eastern English Channel: temperate marine fish communities}

\section{Disturbance}

The fish communities of the Eastern English Channel (EEC) experienced a major shift in both taxonomic and trait structure in 1997 in response to an Atlantic-wide climate oscillation (The Atlantic Multidecadal Oscillation) that led to rapid sea surface warming and oceanographic changes (Auber, Travers-Trolet, Villanueva, \& Ernande, 2015; Ting, Kushnir, Seager, \& Li, 2009). While all sampling sites throughout the EEC were concurrently impacted by a basin-wide climate disturbance, the magnitude of community change was highly variable among sites with some sites experiencing very pronounced shifts and others remaining more stable (Auber, Travers-Trolet, Villanueva, \& Ernande, 2017).

\section{Fish community data}

The fish community of the EEC (area VIId defined by the International Council for the Exploration of the Sea, ICES) has been sampled every October since 1988 during the scientific monitoring campaign the Channel Ground Fish Survey (CGFS). Here, we focused on the study period of 1988 - 2011. The CGFS sampling scheme was spatially stratified by subdividing the EEC into $15^{\prime}$ longitude $\times 15$ ' latitude rectangles where at least one 30 -min haul was made during daylight hours at an average speed of 3.5 knots. A high $(3 \mathrm{~m})$ vertical opening bottom trawl (GOV) with a 10-mm-stretched-mesh-size codend was used. After each haul, all captured fishes were identified and counted. Abundance indices at each sampling station were obtained from the ICES data portal and were standardized to numbers of individuals per $\mathrm{km}^{2}$ (ICES). Because weather sometimes prevents sampling, sites with three 
or more consecutive years of missing data were removed, resulting in 79 total sampling sites. Before analyses, abundance data were $\ln (\mathrm{Ax}+1)$ transformed (where $\mathrm{A}^{*} \min (\mathrm{x})=2$ ) (Auber, Travers-Trolet, Villanueva, \& Ernande, 2017; Van den Brink, Hattink, Bransen, Van Donk, \& Brock, 2000) to reduce the influence of highly dominant species.

\section{Traits}

Following the definition of Violle et al. (2007), we examined community dynamics not only through ecological traits related to energy transfer, but also through traits related to environmental filtering and biological interactions like competition. More precisely, seven traits related to life history, habitat use, and trophic ecology were collected for 73 taxa (67 species, 6 identified to genera only). These included length and age at maturity, fecundity, offspring size, parental care, water column position, and trophic guild (Table S1). Trait data came from FishBase (Froese \& Pauly, 2012), Engelhard, Ellis, Payne, ter Hofstede, \& Pinnegar (2011), and Pecuchet et al. (2017). Traits encompassing life history, trophic ecology, and habitat preferences were chosen as they have known influences over species responses to environmental changes and influences on ecosystem processes (McLean et al., 2018; Villéger, Brosse, Mouchet, Mouillot, \& Vanni, 2017). While some studies have recommended examining trait redundancy uniquely with 'effect' traits, there is much overlap between 'response' and 'effect' traits in marine fishes, and traits used in this study have known links to ecosystem functioning (Villéger, Brosse, Mouchet, Mouillot, \& Vanni, 2017). For example, body size and age at maturity can determine species responses through differences in population turnover and generation time (Perry, Low, Ellis, \& Reynolds, 2005), yet body size is a universal trait controlling mobility, feeding rate, and speciesinteractions, hence impacts on trophic networks and nutrient cycles (Bellwood, Streit, Brandl, 
\& Tebbett, 2019). Resource fluctuations and phenological mismatches can lead to shifts in trophic guild dominance (Hargeby, Andersson, Blindow, \& Johansson, 1994; Thackeray et al., 2016), and trophic shifts can alter energy transfer and food web stability (Mumby et al., 2006). Water column position has been linked to changes in distribution and abundance because pelagic fishes have greater capacity for range shifts (Rijnsdorp, Peck, Engelhard, Möllmann, \& Pinnegar, 2009), but water column position also influences nutrient cycling and benthic-pelagic coupling (Griffiths et al., 2017).

\section{Environmental factors}

We examined environmental factors known to drive fish community dynamics in marine ecosystems, including depth, sea surface temperature (SST), and salinity. Although the majority of species in the English Channel are demersal, sea surface temperature was appropriate because the ecosystem is shallow (mean depth $=63 \mathrm{~m}$ ) and well-mixed, and the majority of species have pelagic eggs and larvae, which are the most vulnerable life stages of marine fishes (Pepin, 1991). Depth was measured in-situ during community sampling, SST data came from the kriging-interpolated Ifremer AVHRR/Pathfinder database (Saulquin \& Gohin, 2010), and salinity data came from the NORWegian ECOlogical Model (NORWECOM), a coupled 3D physical/bio-chemical model of environmental factors for the North Sea and the English Channel (Skogen, Svendsen, Berntsen, Aksnes, \& Ulvestad, 1995). Depth is a major driver of community structure in marine ecosystems as it influences light penetration, temperature and oxygen profiles, water column mixing, and habitat type. SST is a primary driver of species' distributions and abundances globally, and SST warming can profoundly impact marine fish communities, which are highly responsive to changes in temperature (Simpson et al., 2011). Salinity can influence community structure through 
physiological responses, impacts on larval success, and shifts between stenohaline and euryhaline species (Petereit et al., 2009, Sirot et al., 2015). Although chlorophyll- $a$ can also determine community structure through bottom-up control and through larval success and recruitment (Beaugrand, 2004; Capuzzo et al., 2017), spatially-resolved data for chlorophyll$a$ were not available prior to 1998. Spatially-resolved data for fishing pressure were also unavailable prior to 2000, however, the rapid shift in fish communities in the English Channel was driven primarily by climate and not by fishing (Auber, Travers-Trolet, Villanueva, \& Ernande, 2015), and the objective of this study was to examine heterogeneity in community responses following the climatic disturbance.

\section{Seychelles Islands: coral reef-fish communities}

\section{Disturbance}

The Seychelles Islands experienced wide-spread coral mortality following severe coral bleaching during the 1998 El Niño that led to substantial changes in reef fish taxonomic and trait structure (Graham, Jennings, MacNeil, Mouillot, \& Wilson, 2015; Graham et al., 2006). The mass bleaching was severe across the entire inner Seychelles (Graham, Jennings, MacNeil, Mouillot, \& Wilson, 2015; Graham et al., 2006), and of the 21 sites surveyed, all but one site had losses in coral cover, with an average 65\% loss across all sites. Aside from the bleaching, there were no other large-scale disturbances in the inner Seychelles during this timeframe, and other local stressors remained stable (Graham et al., 2006). While differential benthic trajectories following the mass bleaching have been linked to environmental and ecological conditions (Graham, Jennings, MacNeil, Mouillot, \& Wilson, 2015; Nash, Graham, Jennings, Wilson, \& Bellwood, 2016), variation in initial disturbance sensitivity has not yet been investigated.

This article is protected by copyright. All rights reserved. 


\section{Fish community data}

Fish abundance data were collected at 21 sites around the Seychelles Islands using underwater visual census (UVC) in both 1994 (pre-disturbance) and 2005 (post-disturbance). At each site 16 individual $7-\mathrm{m}$ radius $\left(154 \mathrm{~m}^{2}\right)$ stationary point counts were surveyed along the reef slope, and the identity and density of diurnally active, non-cryptic reef fishes were recorded within each count (Graham, Jennings, MacNeil, Mouillot, \& Wilson, 2015, Graham et al., 2006). As with the EEC, abundance data were $\ln (\mathrm{Ax}+1)$ transformed before analyses.

\section{Traits}

While intrinsic differences between the two study ecosystems lead to different trait choices, we attempted to maximize trait overlap between ecosystems. Life-history traits such as fecundity and offspring size are largely undescribed for coral reef fishes; however, length at maturity, age at maturity, and parental care were all available. Seven traits related to life history, habitat use, behavior, and trophic ecology were therefore collected for the 129 species sampled. These included length and age at maturity, parental care, water column position, trophic guild, mobility, and gregariousness (i.e., schooling behavior) (Table S2). Trait data were collected primarily from FishBase (Froese \& Pauly, 2012) and previously published literature (Graham et al., 2011; Graham, Jennings, MacNeil, Mouillot, \& Wilson, 2015; Stuart-Smith et al., 2013; Wilson et al., 2008), while length and age at maturity estimates were derived from the R package FishLife (Thorson, Munch, Cope, \& Gao, 2017). These traits were chosen not only to maximize overlap between ecosystems, but also because they have been previously implicated in reef fish responses to environmental change and influences on ecosystem processes (Graham et al., 2011; Pratchett et al., 2008; Stuart-Smith et al., 2013; Wilson et al., 2008). For example, body size and diet determine energy needs, 
predator-prey relationships, and trophic interactions, parental care determines habitat requirements and habitat modification, gregariousness influences predation vulnerability, nutrient cycling, and resource depletion, and mobility influences home range (i.e., scale of ecological role) and nutrient transfer (Mouillot et al., 2014; Stuart-Smith et al., 2013; Wilson et al., 2008).

\section{Environmental factors}

We examined known environmental drivers of reef-fish community structure, including management status (i.e., openly fished sites vs. marine reserves), depth, coral cover, and reef complexity. Fishing is a primary driver of reef fish community structure and can erode diversity and ecosystem functioning, and thus openly fished sites could be more sensitive to disturbance than marine reserves (Cinner et al., 2018; Houk et al., 2015). Depth controls coral-reef structure through light attenuation and wave exposure (Bridge, Hughes, Guinotte, \& Bongaerts, 2013) while coral cover and complexity can enhance habitat diversity and resource availability (Richardson, Graham, Pratchett, \& Hoey, 2017; Rogers, Blanchard, \& Mumby, 2014). Within each stationary point count, the percent cover of live hard coral was quantified and the structural complexity of the reef was visually estimated (Graham, Jennings, MacNeil, Mouillot, \& Wilson, 2015, Graham et al., 2006). Structural complexity was assigned to one of the five categories: $0=$ no vertical relief, $1=$ low $(<30 \mathrm{~cm})$ and sparse relief, $2=$ low but widespread relief, $3=$ widespread moderately complex $(30-60 \mathrm{~cm})$ relief, $4=$ widespread very complex $(60-100 \mathrm{~cm})$, and $5=$ exceptionally complex $(>1 \mathrm{~m})$ relief, which aligns with several other methods of assessing structural complexity on coral reefs (Wilson, Graham, \& Polunin, 2007). 


\section{Quantifying sensitivity}

\section{Multidimensional trait space}

We first generated a trait space for each ecosystem where species are arranged according to their trait values and distances between species reflect their trait similarity (Maire, Grenouillet, Brosse, \& Villéger, 2015; Mouillot, Graham, Villéger, Mason, \& Bellwood, 2013). We computed Gower dissimilarity matrices of the species by traits table for each ecosystem; Gower dissimilarity is well-adapted for examining traits as it can handle multiple data types (i.e., continuous and categorical) and missing values (Gower, 1971). Trait spaces were then built by ordinating the Gower matrices using principal coordinates analysis (PCoA) (Villéger, Mason, \& Mouillot, 2008). For each ecosystem, we kept the first four axes of trait space, which cumulatively explained nearly $80 \%$ of total variance in both cases. Four axes have been shown to effectively capture community variation while maintaining initial Gower dissimilarity (Maire, Grenouillet, Brosse, \& Villéger, 2015), and Mantel tests revealed that Euclidean distances between species in four-dimensional spaces were strongly correlated with initial Gower distances (EEC: $r=0.96, p<0.001$; Seychelles: $r=0.96, p<0.001$ ). Including additional axes did not greatly improve these relationships ( 6 axes; EEC: $r=0.98$; Seychelles: $r=0.98$ ), demonstrating that the majority of variability in traits was accurately captured with four axes.

\section{Sensitivity}

Using the trait space, we quantified 'sensitivity' as the amount of change in trait structure following disturbance. Large shifts in trait structure indicate low resistance and thus high sensitivity, while small shifts indicate high resistance and low sensitivity. For a given 
ecosystem, we first calculated abundance-weighted community centroids in trait space for all sites in all time periods (Figure 1a). Within the trait space, the location of any given community in any given year is defined as the abundance-weighted centroid of all species in the community (Figure 1a). Thus, the movement of a community in the trait space can be used to quantify changes in trait structure through time. We therefore calculated sensitivity as the Euclidean distance between a community's position in trait space before and after disturbance (Figure 1b). This quantifies the amount of distance each community moved in trait space following a disturbance, where sites with larger movements display higher sensitivity and sites with smaller movements display higher resistance. In the EEC, where an abrupt shift occurred in the middle of a long time series, for each community, we calculated the distance between the average positon of all years before and all years after the shift (1997), while in the Seychelles, for each site, we calculated the distance between 1994 (prebleaching) and 2005 (post-bleaching).

\section{Trait redundancy}

Redundancy quantifies the degree to which species in a community share similar ecological characteristics, i.e., whether ecological roles are supported by few or many species and individuals. Multiple methods exist for calculating trait redundancy that are mostly based on deriving ecological groups or calculating distances between adjacent species in multidimensional space (Bruno, Gutiérrez-Cánovas, Sánchez-Fernández, Velasco, \& Nilsson, 2016; Micheli \& Halpern, 2005; Mouillot et al., 2014; Pillar et al., 2013; Ricotta et al., 2016). However, such indices require subjective choices such as the number of ecological groups or the cut-offs for nearest-neighbor calculations (e.g., nearest single neighbor vs. nearest five neighbors), and some indices only work with categorical traits (Bruno, Gutiérrez-Cánovas, 
Sánchez-Fernández, Velasco, \& Nilsson, 2016; Ricotta et al., 2016). Furthermore, most indices do not account for abundance or evenness, which can drastically impact trait redundancy as a higher number of individuals, not only species, supporting the same ecological role can provide greater buffering capacity against disturbances, and high evenness across species should lead to greater average redundancy than a community dominated by few species (D'agata et al., 2016). We therefore quantified trait redundancy following de Bello, Lepš, Lavorel, \& Moretti (2007) \& Ricotta et al. (2016), where trait redundancy is defined as the degree to which a community is 'saturated' with similar traits, and is calculated as the difference between taxonomic diversity (Simpson's index) and trait diversity (Rao's quadratic entropy). In this way, communities with the same level of trait diversity but different levels of taxonomic diversity (or vice versa) will vary in trait redundancy, where a community with either more ecologically-similar species or higher species diversity will have higher redundancy (de Bello, Lepš, Lavorel, \& Moretti, 2007; Ricotta et al., 2016). Previous studies quantifying trait redundancy using this metric found significant relationships with community stability and environmental filtering, demonstrating the utility for examining relationships between redundancy and community dynamics while integrating species abundance distributions (Bruno, Gutiérrez-Cánovas, Sánchez-Fernández, Velasco, \& Nilsson, 2016; Kang et al., 2015; Pillar et al., 2013). Additionally, this metric of trait redundancy is calculated at the community level using continuous data, and does not require defining ecological groups. Initial trait redundancy (i.e., pre-disturbance) was calculated for all fish communities in both ecosystems using the R package SYNCSA.

This article is protected by copyright. All rights reserved. 


\section{Generalized Linear Models (GLMs)}

To consider the influences of environmental factors, for each site we calculated the change in each variable following disturbance (mean before vs mean after) rather than using temporally-averaged spatial variables, to avoid using static independent variables to predict dynamic dependent variables. Thus, changes in local environmental factors were used to predict changes in community trait structure. For instance, while the EEC was impacted by an Atlantic-wide climate oscillation and associated ocean warming, local-scale variability in SST or salinity change could explain variability in community responses. Depth was the only factor included in all statistical models, as it is a permanent environmental condition (on ecological time scales). Therefore, in the EEC, we built generalized linear models (GLMs, Gaussian distribution) testing the influences of i) the initial position of each fish community in trait space (PCoA 1 and PCoA 2 scores), ii) initial trait redundancy, iii) species richness, iv) depth, v) changes in local SST, and vi) changes in local salinity on community sensitivity. In the Seychelles, we used GLMs to test the influences of i) the initial position of each fish community in trait space (PCoA1 and PCoA2 scores), ii) initial trait redundancy, iii) species richness, iv) depth, v) percent change in coral cover, vi) percent change in reef structural complexity, and vii) management status on sensitivity. While sensitivity was calculated in four-dimensional space, only the first two PCoA axes were included in GLMs since they carry the majority of ecological-trait variation $(>50 \%)$, and are thus sufficient to test the hypothesis that initial trait structure influences sensitivity. To identify the relative importance of independent variables, we used the dredge function from the R package MuMin, which calculates Akaike weights for each variable by comparing Akaike Information Criteria across the set of models containing all possible combinations of variables (Arruda Almeida, Green, Sebastián-González, \& dos Anjos, 2018; Barton \& Barton, 2018). Next, to assess the robustness of the relationships between sensitivity and independent variables, we re-ran the 
analyses using all combinations of six traits out of seven. For each model repetition, we calculated the corresponding Akaike weights, and independent variables were ranked according to their mean Akaike weights across all models (full model and all combinations of six traits). Finally, the full GLMs were checked for spatial-autocorrelation by testing model residuals with Moran's I.

\section{Null Models}

To examine whether the relationships between sensitivity and i) initial trait structure, or ii) initial trait redundancy were significantly different than expected by chance, we built null models examining the slope of the linear regression between sensitivity and each metric, following Fukami, Martijn, Mortimer, \& Putten (2005). For each null model we randomly permutated species abundances (i.e., abundances were randomly shuffled between species), re-calculated abundance-weighted community centroids in trait space, re-calculated trait redundancy, and re-computed the corresponding linear models. This process was repeated 1000 times and the corresponding linear models were used to build null distributions of 1000 slopes. The actual observed slopes between sensitivity and i) initial position in trait space, and ii) initial trait redundancy were then compared to the resulting null distributions.

\section{Results}

\section{Climatic disturbance in a temperate marine fish community}

In the EEC, the first two axes of trait space captured $52 \%$ of overall variation in fish trait structure across the 73 taxa (Figure 2a), while the third and fourth axes explained an additional $24 \%$. The first axis of trait space was primarily characterized by differences 
between large-bodied, long-lived species with large offspring (lower values) vs. smallbodied, short-lived pelagic species and detritivores (higher values), while the second axis was characterized by differences between carcinophages and benthopiscivores with high parental care and large offspring (higher values) vs. pelagic species, planktivores, and detritivores with low parental care and small offspring (lower values) (Figure 2a; Figure S2). We found that the distance each community moved across the trait space following the disturbance was significantly correlated to the initial position of each community along the first and second axes of space, as communities with lower PCoA 1 and PCoA 2 values experienced higher changes in trait structure following the disturbance (PCoA 1: $r=-0.25, p<0.05$; PCoA 2: $r=$ $-0.27, p=0.01$; Figure 2a,b; Figure 3a; Figure S1). We found that distance moved was also significantly and negatively correlated to initial trait redundancy: fish communities with higher trait redundancy were more resistant and had less pronounced shifts $(r=-0.50, p<$ 0.0001; Figure 3b). GLMs then ranked PCoA 2 position, trait redundancy, and local salinity changes as the most important variables predicting the distance moved by each community across the trait space (Top 3 variables, Table 1), with secondary contributions by local temperature changes, depth, PCoA 1 position, and species richness. No spatial autocorrelation was found in the model residuals (Moran's I, $p=0.41$ ), indicating the results were robust to spatial effects and that we did not omit major factors in the models.

Null models indicated that the slope of the relationship between sensitivity and initial PCoA 2 position was larger than expected by chance, albeit not significantly, as the observed slope was smaller than the $95 \%$ most extreme expected values (Figure 4a). However, the slope of the relationship between sensitivity and initial trait redundancy was significantly larger than expected by chance, as the observed slope was greater than $95 \%$ of slopes in the null distribution (Figure 4b). 


\section{Reef-fish community responses to coral bleaching}

In the Seychelles, the first two axes of trait space captured $52 \%$ of overall variation in fish trait structure for the 129 species (Figure 2c), while the third and fourth axes explained an additional $22 \%$. The first axis of trait space was primarily characterized by differences between species with large size and age at maturity, high mobility, piscivorous diets, and solitary behavior (lower values) vs. small, fast-growing planktivores and corallivores with high parental care (i.e., hide and guard eggs within coral habitats), and schooling behavior (higher values), while the second axis was characterized by differences between invertivore feeders with solitary behavior and closer association the benthos (lower values) vs. piscivores and microphages with higher position in the water column (higher values) (Figure 2b; Figure S3). We found that the distance moved by each community between the two time periods (1994 and 2005) was significantly correlated to the initial position of each community along PCoA axis 1, as communities with higher PCoA 1 scores had larger changes in trait structure $(r=0.56, p<0.01$; Figure 2d; Figure 3d; Figure S1). We next found that the distance moved by each community was also significantly and negatively correlated to initial trait redundancy, as communities with higher trait redundancy were less sensitive and more resistant to changes in trait structure $(r=-0.59, p<0.01$; Figure $3 \mathrm{e})$. GLMs then ranked trait redundancy, PCoA 1 position, and coral cover change as the most important independent variables predicting the distance moved by each community in trait space (Top 3 variables, Table 1) with secondary contributions by depth, PCoA 2 position, species richness, reef complexity change, and management status. Finally, Moran's I revealed that there was no spatial autocorrelation in the model residuals $(p=0.49)$.

This article is protected by copyright. All rights reserved. 
Null models indicated that the slope of the relationship between sensitivity and both i) initial PCoA 1 position and ii) initial trait redundancy were significantly larger than expected by chance, as the observed slopes were greater than $95 \%$ and $99 \%$ of slopes in the null distributions, respectively (Figure 4c,d).

\section{Discussion}

Despite wide belief that trait structure and redundancy can determine community sensitivity to disturbance, little evidence exists from natural systems over large temporal and spatial scales. Additionally, while functional ecology has operated on the presumed buffering capacity of trait redundancy, few studies have quantitatively demonstrated links between trait redundancy and community sensitivity outside of controlled experiments. Here, we present one of first studies using long-term data in two distinct ecosystems showing that trait structure and redundancy may determine community sensitivity to disturbance and that trait redundancy may buffer communities against environmental change. Past experimental and small-scale observational studies have shown that higher levels of trait redundancy can maintain community stability in the face of environmental change (Allison \& Martiny, 2008; Loreau, 2004; Rosenfeld, 2002; Wohl, Arora, \& Gladstone, 2004); however, here we used datasets spanning nearly 25 years to examine changes in large, natural ecosystems in both temperate and tropical environments. Our findings support long-standing theory that higher diversity (i.e., richness and abundance) supporting ecological roles can generate greater community stability, reducing sensitivity to climatic disturbances (Elmqvist et al., 2003; Rosenfeld, 2002; Walker, 1992). 
As disturbances in both ecosystems were related to climate warming, our results provide insight for understanding biodiversity responses to climate change. Not only were communities with lower trait redundancy more sensitive to climatic disturbances, but dominance by certain trait values rendered communities particularly sensitive to disturbance. For instance, in the EEC, dominance by small, r-selected pelagics led to greater shifts in trait structure through time as small pelagic species are highly responsive to environmental change, particularly warming and changes in oceanographic processes (Alheit et al., 2014; Lindegren, Checkley, Rouyer, MacCall, \& Stenseth, 2013; Rijnsdorp, Peck, Engelhard, Möllmann, \& Pinnegar, 2009). Pelagic fishes are also highly mobile and can quickly migrate or shift distribution, whereas demersal and reef-associated taxa may have greater site fidelity and less response capacity (Alheit et al., 2014; Lindegren, Checkley, Rouyer, MacCall, \& Stenseth, 2013; McLean et al. 2018; Rijnsdorp, Peck, Engelhard, Möllmann, \& Pinnegar, 2009). In the Seychelles, communities more dominated by small, gregarious corallivores and planktivores were more impacted by large-scale coral mortality, which is consistent with studies showing that small-bodied fishes feeding on and around corals typically decline following disturbance (Graham et al., 2007; Pratchett et al., 2008; Richardson, Graham, Pratchett, Eurich, \& Hoey, 2018). While the climatic vulnerability of small pelagics and small corallivores is well-documented, our approach demonstrates that initial trait structure can predict community sensitivity to climatic disturbance, which is likely applicable across ecosystems and taxa. Our results therefore highlight the need to identify key traitenvironment relationships in marine ecosystems worldwide to anticipate how climate warming might impact current and future communities through changes in trait structure.

This article is protected by copyright. All rights reserved. 
While certain trait structures rendered communities more sensitive to disturbance, communities with higher trait redundancy were more resistant. Trait redundancy may buffer communities through multiple underlying mechanisms. According to the portfolio effect, if community structure is supported by many ecologically-similar species and these species exhibit asynchronous responses to disturbance, the lesser-impacted species should maintain overall community structure (Loreau \& de Mazancourt, 2013; Oliver et al., 2015; Yachi \& Loreau, 1999). High evenness, where each ecological role is supported by similar species richness and abundance, should also increase community resistance, whereas communities over-represented by few, dominant species may leave some ecological roles with low redundancy and weak insurance (Flöder \& Hillebrand, 2012; Oliver et al., 2015; Wittebolle et al., 2009). For instance, if evenness is low and dominant species are sensitive to disturbance, communities will be highly impacted, but if evenness is high, resistant species may maintain or recover community structure (Flöder \& Hillebrand, 2012; Wittebolle et al., 2009). Additionally, redundancy in species interactions may buffer communities by increasing food web stability. For example, loss of key trophic interactions can destabilize community structure (Kuiper et al., 2015), and trophic redundancy has been shown to reduce vulnerability to cascades (Sanders, Thébault, Kehoe, \& van Veen, 2018). In the EEC, trait diversity was relatively similar across communities, while taxonomic diversity was higher along the coasts, leading to greater trait redundancy, as ecological roles were supported by more species and greater abundances (Figure S6). Communities exhibiting the greatest shifts in trait structure had low species richness and abundance, meaning some ecological roles had only limited support. Although pelagic fishes were highly impacted throughout the ecosystem, resistant communities had higher richness and abundance of pelagics, which appeared to buffer them against changes in trait structure. For example, horse mackerel exhibited exceptional declines (Auber, Travers-Trolet, Villanueva, \& Ernande, 2015; Auber, 
Travers-Trolet, Villanueva, \& Ernande, 2017) and communities mainly dominated by horse mackerel suffered major shifts from pelagic to demersal structure, whereas communities with large abundances of not only horse mackerel but also sprat, herring, and Atlantic mackerel (ecologically-similar species) had greater capacity to maintain initial structure (Figure 5). It therefore appears that the combination of higher richness and evenness supporting similar levels of trait diversity in the EEC lead to higher resistance and lower sensitivity.

It is also important to note that higher trait diversity does not necessarily correspond to higher overall trait redundancy, as ecologically-simple communities can have high redundancy (Casatti et al., 2015; Fonseca \& Ganade, 2001; Mouillot et al., 2014). In the Seychelles, the most impacted communities were actually those with the highest trait diversity - species in these communities varied greatly in trait composition. However, taxonomic diversity was more similar among communities, indicating that, although impacted communities had high trait diversity, individual ecological roles were supported by fewer species and individuals (Figure S7). Thus, higher trait redundancy in resistant communities resulted from similar levels of richness and abundance being shared among fewer ecological roles. Additionally, it is important to note that the impact of ecological disturbances and the buffering capacity of trait redundancy depend on the type of disturbance and on which ecological roles are affected. For instance, the least impacted communities in the Seychelles were intuitively those with lower abundances of small corallivores. Thus, while the ecological roles supported by these species, e.g., shaping coral diversity (Cole, Pratchett, \& Jones, 2008), were most impacted following disturbance, these roles were already low in unaffected communities. Hence, unaffected communities had high trait redundancy within ecological roles (e.g., large-bodied invertivores) that were not heavily impacted by disturbance. Yet, if the impacted ecological roles had been highly redundant, sensitive communities may have been more resistant. For instance, communities more 
characterized by small-bodied, site-attached corallivores and planktivores had higher sensitivity. However, corallivores and planktivores accounted for only $12 \%$ of all species and only $14 \%$ of trophic guild abundance on average, whereas invertivores accounted for $43 \%$ of species and $46 \%$ of trophic guild abundance. Thus, if small-bodied corallivores and planktivores had greater initial redundancy, sensitive communities may have been buffered against disturbance, particularly through additional species with asynchronous environmental responses.

While our findings support the conclusion that trait redundancy may buffer communities against disturbance, alternative explanations are possible. For example, trait structure and redundancy are intrinsically correlated with environmental conditions, and we found that sensitivity was also related to environmental change in both ecosystems. In the EEC, salinity changes may have contributed to declines in species with small pelagic eggs and larvae, as salinity influences egg buoyancy and survival (Nissling, Nyberg, \& Petereit, 2017; Petereit et al., 2009; Sundby \& Kristiansen, 2015). However, salinity changes in the EEC were much lower than those normally reported to impact fish community structure (Petereit et al., 2009; Sirot et al., 2015). In the Seychelles, we found that fish communities experiencing greater losses of coral cover and at shallower depths had higher sensitivity and lower resistance to disturbance, which is in line with previous studies showing that coral-loss reorganizes reef fish communities (Richardson, Graham, Pratchett, Eurich, \& Hoey, 2018) and that shallower communities are more sensitive to disturbances like bleaching (Bridge, Hughes, Guinotte, \& Bongaerts, 2013). If sensitivity in the Seychelles was driven by greater environmental impacts, the apparent buffering capacity of trait redundancy could be an artifact of lower redundancy on reefs with greater coral loss. However, it is likely that both initial biological structure and local environmental changes are driving sensitivity and their influences may be synergistic. 
As with all trait-based approaches, the choice and number of traits may have important impacts on the patterns of trait diversity and redundancy (Lepš, de Bello, Lavorel, \& Berman, 2006; Violle \& Jiang, 2009; Violle et al., 2007). For example, communities may have little redundancy along one niche axis, but high redundancy along another, and contrasting trends in the two axes could blur redundancy patterns (Micheli \& Halpern, 2005; Spasojevic \& Suding, 2012). However, multiple traits are needed to capture nuances among species, as combinations of traits (e.g., habitat type and life history) may act synergistically, leading to higher or lower disturbance sensitivity (Mouillot, Graham, Villéger, Mason, \& Bellwood, 2013; Villéger, Brosse, Mouchet, Mouillot, \& Vanni, 2017; Villéger, Miranda, Hernández, \& Mouillot, 2010). However, re-running our analyses with all combinations of six out of seven traits did not substantially modify results, as trait structure and redundancy emerged as the most important explanatory factors of sensitivity (Figure S4, Figure S5).

While we examined the influence of biological structure on community sensitivity to disturbance, future studies should also examine the environmental drivers of trait redundancy itself. Linking gradients in environmental condition or human stressors to trait redundancy could be particularly informative for resource management. If human stressors are reducing trait redundancy, management strategies could be adapted to enhance redundancy for increased resilience against future disturbances. In the Seychelles Islands, management status was not linked to environmental sensitivity, yet other natural and human drivers such as productivity or watershed pollution could have shaped initial trait structure and redundancy. While we were unable to quantify the influence of historical fishing pressure on sensitivity in the English Channel, past studies have concluded that overfishing may have rendered fish communities more sensitive to climatic changes by removing large demersal predators (McLean et al., 2018; Molfese, Beare, \& Hall-Spencer, 2014). Thus, identifying the natural and anthropogenic drivers of ecological-trait structure and redundancy should be prioritized 
in future studies and resilience assessments. Future studies should also attempt to identify thresholds of ecological trait and trait redundancy values to reveal tipping points in ecosystem stability that could be used as tangible management targets for maintaining resilience. As biodiversity loss threatens ecosystem functioning worldwide, identifying and conserving the mechanisms of community stability will be critical to maintaining the diversity needed to support ecosystem services.

\section{Acknowledgements}

We sincerely thank all scientists who contributed to this work, especially those who participated in fisheries monitoring and data collection in the Eastern English Channel and Seychelles Islands. In particular we thank IFREMER, the Seychelles Fishing Authority, Seychelles Marine Parks Authority, and Nature Seychelles whose logistical contributions made this work possible, and Simon Jennings who collected the 1994 Seychelles data. We also thank le centre de synthèse et d'analyse sur la biodiversité (CESAB) for providing a collaborative research environment that helped advance this work. This study was supported by Electricité de France, IFREMER, Région Hauts-de-France (RESTICLIM project), and the Total Foundation (FUTURE REEFS project).

This article is protected by copyright. All rights reserved. 


\section{References}

Alheit, J., Licandro, P., Coombs, S., Garcia, A., Giráldez, A., Santamaría, M. T. G., ... Tsikliras, A. C. (2014). Atlantic Multidecadal Oscillation (AMO) modulates dynamics of small pelagic fishes and ecosystem regime shifts in the eastern North and Central Atlantic. Journal of Marine Systems, 131, 21-35. https://doi.org/10.1016/j.jmarsys.2013.11.002

Allison, S. D., \& Martiny, J. B. H. (2008). Resistance, resilience, and redundancy in microbial communities. Proceedings of the National Academy of Sciences, 105, 11512. https://doi.org/10.1073/pnas.0801925105

Arruda Almeida, B. D., Green, A. J., Sebastián-González, E., \& dos Anjos, L. (2018). Comparing species richness, trait diversity and functional composition of waterbird communities along environmental gradients in the neotropics. PLoS ONE, 13(7), e0200959. https://doi.org/10.1371/journal.pone.0200959

Auber, A., Travers-Trolet, M., Villanueva, M. C., \& Ernande, B. (2015). Regime shift in an exploited fish community related to natural climate oscillations. PLOS ONE, 10(7). https://doi.org/10.1371/journal.pone.0129883

Auber, A., Travers-Trolet, M., Villanueva, M. C., \& Ernande, B. (2017). A new application of principal response curves for summarizing abrupt and cyclic shifts of communities over space. Ecosphere, 8(12), e02023-n/a. https://doi.org/10.1002/ecs2.2023

Barros, C., Thuiller, W., Georges, D., Boulangeat, I., \& Münkemüller, T. (2016). Ndimensional hypervolumes to study stability of complex ecosystems. Ecology Letters, 19(7), 729-742. https://doi.org/10.1111/ele.12617

Barton, K., \& Barton, M. K. (2018). Package "MuMIn."

Beaugrand, G. (2004). The North Sea regime shift: evidence, causes, mechanisms and consequences. Progress in Oceanography, 60(2), 245-262.

This article is protected by copyright. All rights reserved. 
Beaugrand, G., Edwards, M., Raybaud, V., Goberville, E., \& Kirby, R. R. (2015). Future vulnerability of marine biodiversity compared with contemporary and past changes. Nature Climate Change, 5, 695.

Bellard, C., Bertelsmeier, C., Leadley, P., Thuiller, W., \& Courchamp, F. (2012). Impacts of climate change on the future of biodiversity: Biodiversity and climate change. Ecology Letters, 15(4), 365-377. https://doi.org/10.1111/j.1461-0248.2011.01736.x

Bellwood, D. R., Streit, R. P., Brandl, S. J., \& Tebbett, S. B. (2019). The meaning of the term "function" in ecology: A coral reef perspective. Functional Ecology. https://doi.org/10.1111/1365-2435.13265

Bozec, Y. M., O’Farrell, S., Bruggemann, J. H., Luckhurst, B. E., \& Mumby, P. J. (2016). Tradeoffs between fisheries harvest and the resilience of coral reefs. Proceedings of the National Academy of Sciences, 113(16), 4536-4541.

Bridge, T. C. L., Hughes, T. P., Guinotte, J. M., \& Bongaerts, P. (2013). Call to protect all coral reefs. Nature Climate Change, 3, 528 .

Bruno, D., Gutiérrez-Cánovas, C., Sánchez-Fernández, D., Velasco, J., \& Nilsson, C. (2016). Impacts of environmental filters on trait redundancy in riparian vegetation. Journal of Applied Ecology, 53(3), 846-855. https://doi.org/10.1111/1365-2664.12619

Burkepile, D. E., \& Hay, M. E. (2008). Herbivore species richness and feeding complementarity affect community structure and function on a coral reef. Proceedings of the National Academy of Sciences. https://doi.org/10.1073/pnas.0801946105

Cadotte, M. W. (2017). Functional traits explain ecosystem function through opposing mechanisms. Ecology Letters, 20(8), 989-996.

This article is protected by copyright. All rights reserved. 
Capuzzo, E., Lynam, C. P., Barry, J., Stephens, D., Forster, R. M., Greenwood, N., ... Engelhard, G. H. (2017). A decline in primary production in the North Sea over 25 years, associated with reductions in zooplankton abundance and fish stock recruitment. Global Change Biology, 24(1), e352-e364. https://doi.org/10.1111/gcb.13916

Casatti, L., Teresa, F. B., Zeni, J. de O., Ribeiro, M. D., Brejão, G. L., \& Ceneviva-Bastos, M. (2015). More of the same: high trait redundancy in stream fish assemblages from tropical agroecosystems. Environmental Management, 55(6), 1300-1314. https://doi.org/10.1007/s00267-015-0461-9

Cheung, W. W., Reygondeau, G., \& Frölicher, T. L. (2016). Large benefits to marine fisheries of meeting the 1.5 C global warming target. Science, 354(6319), 1591-1594.

Cinner, J. E., Maire, E., Huchery, C., MacNeil, M. A., Graham, N. A., Mora, C., ... Hicks, C. C. (2018). Gravity of human impacts mediates coral reef conservation gains. Proceedings of the National Academy of Sciences, 201708001.

Cole, A.J., Pratchett, M.S., \& Jones, G.P. (2008). Diversity and functional importance of coral-feeding fishes on tropical coral reefs. Fish and Fisheries, 9(3), 286-307. https://doi.org/10.1111/j.1467-2979.2008.00290.x

Craven, D., Eisenhauer, N., Pearse, W. D., Hautier, Y., Isbell, F., Roscher, C., .. Manning, P. (2018). Multiple facets of biodiversity drive the diversity-stability relationship. Nature Ecology \& Evolution, 2(10), 1579-1587. https://doi.org/10.1038/s41559-018$0647-7$

D’agata, S., Vigliola, L., Graham, N. A. J., Wantiez, L., Parravicini, V., Villéger, S., ... Mouillot, D. (2016). Unexpected high vulnerability of functions in wilderness areas: evidence from coral reef fishes. Proceedings of the Royal Society B: Biological Sciences, 283(1844), 20160128. https://doi.org/10.1098/rspb.2016.0128 
de Bello, F., Lepš, J., Lavorel, S., \& Moretti, M. (2007). Importance of species abundance for assessment of trait composition: an example based on pollinator communities. Community Ecology, 8(2), 163-170.

Dee, L. E., Miller, S. J., Peavey, L. E., Bradley, D., Gentry, R. R., Startz, R., ... Lester, S. E. (2016). Trait diversity of catch mitigates negative effects of temperature variability on fisheries yields. Proceedings of the Royal Society B: Biological Sciences, 283(1836). https://doi.org/10.1098/rspb.2016.1435

Díaz, S., \& Cabido, M. (2001). Vive la difference: plant trait diversity matters to ecosystem processes. Trends in Ecology \& Evolution, 16(11), 646-655.

Elmqvist, T., Folke, C., Nystrom, M., Peterson, G., Bengtsson, J., Walker, B., \& Norberg, J. (2003). Response diversity, ecosystem change, and resilience. Frontiers in Ecology and the Environment, 1(9), 488. https://doi.org/10.2307/3868116

Engelhard, G. H., Ellis, J. R., Payne, M. R., ter Hofstede, R., \& Pinnegar, J. K. (2011). Ecotypes as a concept for exploring responses to climate change in fish assemblages. ICES Journal of Marine Science, 68(3), 580-591. https://doi.org/10.1093/icesjms/fsq183

Flöder S, \& Hillebrand H. (2012). Species traits and species diversity affect community stability in a multiple stressor framework. Aquatic Biology, 17(3), 197-209.

Fonseca, C. R., \& Ganade, G. (2001). Species trait redundancy, random extinctions and the stability of ecosystems. Journal of Ecology, 89(1), 118-125. https://doi.org/10.1046/j.1365-2745.2001.00528.x

Froese, R., \& Pauly, D. (2012). FishBase (www database). Retrieved from http://www.fishbase.org.

This article is protected by copyright. All rights reserved. 
Fukami, T., Martijn, B.T., Mortimer, S.R., \& Putten, W.H. (2005). Species divergence and trait convergence in experimental plant community assembly. Ecology Letters, 8(12), 1283-1290. https://doi.org/10.1111/j.1461-0248.2005.00829.x

Gower, J. C. (1971). A general coefficient of similarity and some of its properties. Biometrics, 857-871.

Graham, N. A. J., Chabanet, P., Evans, R. D., Jennings, S., Letourneur, Y., Aaron MacNeil, M., ... Wilson, S. K. (2011). Extinction vulnerability of coral reef fishes. Ecology Letters, 14(4), 341-348. https://doi.org/10.1111/j.1461-0248.2011.01592.x

Graham, N. A.J., Jennings, S., MacNeil, M. A., Mouillot, D., \& Wilson, S. K. (2015). Predicting climate-driven regime shifts versus rebound potential in coral reefs. Nature, 518(7537), 94-97.

Graham, N. A.J., Wilson, S. K., Jennings, S., Polunin, N. V., Bijoux, J. P., \& Robinson, J. (2006). Dynamic fragility of oceanic coral reef ecosystems. Proceedings of the National Academy of Sciences, 103(22), 8425-8429.

Graham, N. A.J, Wilson, S. K., Jennings, S., Polunin, N. V., Robinson, J., Bijoux, J. P., \& Daw, T. M. (2007). Lag effects in the impacts of mass coral bleaching on coral reef fish, fisheries, and ecosystems. Conservation Biology, 21(5), 1291-1300.

Griffiths, J. R., Kadin, M., Nascimento, F. J. A., Tamelander, T., Törnroos, A., Bonaglia, S., ... Winder, M. (2017). The importance of benthic-pelagic coupling for marine ecosystem functioning in a changing world. Global Change Biology, 23(6), 21792196. https://doi.org/10.1111/gcb.13642

Gross, N., Le Bagousse-Pinguet, Y., Liancourt, P., Berdugo, M., Gotelli, N. J., \& Maestre, F. T. (2017). Functional trait diversity maximizes ecosystem multifunctionality. Nature Ecology \& Evolution, 1, 0132. 
Hargeby, A., Andersson, G., Blindow, I., \& Johansson, S. (1994). Trophic web structure in a shallow eutrophic lake during a dominance shift from phytoplankton to submerged macrophytes. Hydrobiologia, 279(1), 83-90. https://doi.org/10.1007/BF00027843

Heenan, A., Hoey, A. S., Williams, G. J., \& Williams, I. D. (2016). Natural bounds on herbivorous coral reef fishes. Proceedings of the Royal Society B: Biological Sciences, 283(1843), 20161716. https://doi.org/10.1098/rspb.2016.1716

Heilpern, S. A., Weeks, B. C., \& Naeem, S. (2018). Predicting ecosystem vulnerability to biodiversity loss from community composition. Ecology, 99(5), 1099-1107.

Houk, P., Camacho, R., Johnson, S., McLean, M., Maxin, S., Anson, J., ... van Woesik, R. (2015). The micronesia challenge: assessing the relative contribution of stressors on coral reefs to facilitate science-to-management feedback. PloS ONE, 10(6), e0130823.

Houk, P., Cuetos-Bueno, J., Tibbatts, B., \& Gutierrez, J. (2018). Variable density dependence and the restructuring of coral-reef fisheries across 25 years of exploitation. Scientific Reports, 8(1), 5725. https://doi.org/10.1038/s41598-018-23971-6

Isbell, F., Craven, D., Connolly, J., Loreau, M., Schmid, B., Beierkuhnlein, C., ... Eisenhauer, N. (2015). Biodiversity increases the resistance of ecosystem productivity to climate extremes. Nature, 526, 574 .

Kang, S., Ma, W., Li, F. Y., Zhang, Q., Niu, J., Ding, Y., ... Sun, X. (2015). Trait redundancy instead of species redundancy determines community stability in a typical steppe of inner Mongolia. PLoS ONE, 10(12), e0145605. https://doi.org/10.1371/journal.pone.0145605

Kuiper, J. J., van Altena, C., de Ruiter, P. C., van Gerven, L. P. A., Janse, J. H., \& Mooij, W. M. (2015). Food-web stability signals critical transitions in temperate shallow lakes. Nature Communications, 6, 7727. 
Laliberté, E., Wells, J. A., DeClerck, F., Metcalfe, D. J., Catterall, C. P., Queiroz, C., ... Fraterrigo, J. M. (2010). Land-use intensification reduces trait redundancy and response diversity in plant communities. Ecology Letters, 13(1), 76-86.

Lepš, J., de Bello, F., Lavorel, S., \& Berman, S. (2006). Quantifying and interpreting trait diversity of natural communities: practical considerations matter. Preslia, 78(4), $481-501$.

Lindegren, M., Checkley, D. M., Rouyer, T., MacCall, A. D., \& Stenseth, N. C. (2013). Climate, fishing, and fluctuations of sardine and anchovy in the California Current. Proceedings of the National Academy of Sciences, 110(33), 13672. https://doi.org/10.1073/pnas.1305733110

Liu, X., Trogisch, S., He, J.-S., Niklaus, P. A., Bruelheide, H., Tang, Z., .. Ma, K. (2018). Tree species richness increases ecosystem carbon storage in subtropical forests. Proceedings of the Royal Society B: Biological Sciences, 285(1885). https://doi.org/10.1098/rspb.2018.1240

Loreau, M. (2004). Does trait redundancy exist? Oikos, 104(3), 606-611. https://doi.org/10.1111/j.0030-1299.2004.12685.x

Loreau, M., \& de Mazancourt, C. (2013). Biodiversity and ecosystem stability: a synthesis of underlying mechanisms. Ecology Letters, 16(s1), 106-115. https://doi.org/10.1111/ele.12073

Maire, E., Grenouillet, G., Brosse, S., \& Villéger, S. (2015). How many dimensions are needed to accurately assess trait diversity? A pragmatic approach for assessing the quality of trait spaces: Assessing trait space quality. Global Ecology and Biogeography, 24(6), 728-740. https://doi.org/10.1111/geb.12299 
McLean, M. J., Cuetos-Bueno, J., Nedlic, O., Luckymiss, M., \& Houk, P. (2016). Local stressors, resilience, and shifting baselines on coral reefs. PLOS ONE, 11(11). https://doi.org/10.1371/journal. pone.0166319

McLean, M., Mouillot, D., Lindegren, M., Engelhard, G., Villéger, S., Marchal, P., ... Auber, A. (2018). A climate-driven functional inversion of connected marine ecosystems. Current Biology, 28(22), 3654-3660.e3. https://doi.org/10.1016/j.cub.2018.09.050

Mellin, C., Bradshaw, C., Fordham, D., \& Caley, M. (2014). Strong but opposing $\beta$ diversity-stability relationships in coral reef fish communities. Proceedings of the Royal Society of London B: Biological Sciences, 281(1777), 20131993.

Micheli, F., \& Halpern, B. S. (2005). Low trait redundancy in coastal marine assemblages. Ecology Letters, 8(4), 391-400.

Molfese, C., Beare, D., \& Hall-Spencer, J. M. (2014). Overfishing and the Replacement of Demersal Finfish by Shellfish: An Example from the English Channel. PLoS ONE, 9(7), e101506. https://doi.org/10.1371/journal.pone.0101506

Mora, C., Caldwell, I. R., Caldwell, J. M., Fisher, M. R., Genco, B. M., \& Running, S. W. (2015). Suitable Days for Plant Growth Disappear under Projected Climate Change: Potential Human and Biotic Vulnerability. PLoS Biology, 13(6), e1002167. https://doi.org/10.1371/journal.pbio.1002167

Mouillot, D., Villeger, S., Parravicini, V., Kulbicki, M., Arias-Gonzalez, J. E., Bender, M., ... Bellwood, D. R. (2014). Functional over-redundancy and high functional vulnerability in global fish faunas on tropical reefs. Proceedings of the National Academy of Sciences, 111(38), 13757-13762. https://doi.org/10.1073/pnas.1317625111 
Mouillot, D., Graham, N. A. J., Villéger, S., Mason, N. W. H., \& Bellwood, D. R. (2013). A functional approach reveals community responses to disturbances. Trends in Ecology \& Evolution, 28(3), 167-177. https://doi.org/10.1016/j.tree.2012.10.004

Mumby, P. J., Dahlgren, C. P., Harborne, A. R., Kappel, C. V., Micheli, F., Brumbaugh, D. R., ... Sanchirico, J. N. (2006). Fishing, trophic cascades, and the process of grazing on coral reefs. Science, 311(5757), 98-101.

Nash, K. L., Graham, N. A., Jennings, S., Wilson, S. K., \& Bellwood, D. R. (2016). Herbivore cross-scale redundancy supports response diversity and promotes coral reef resilience. Journal of Applied Ecology, 53(3), 646-655.

Nissling, A., Nyberg, S., \& Petereit, C. (2017). Egg buoyancy of flounder, Platichthys flesus, in the Baltic Sea—adaptation to salinity and implications for egg survival. Fisheries Research, 191, 179-189.

Nolan, C., Overpeck, J. T., Allen, J. R. M., Anderson, P. M., Betancourt, J. L., Binney, H. A., ... Jackson, S. T. (2018). Past and future global transformation of terrestrial ecosystems under climate change. Science, 361(6405), 920. https://doi.org/10.1126/science.aan5360

Oliver, T. H., Heard, M. S., Isaac, N. J., Roy, D. B., Procter, D., Eigenbrod, F., ... Petchey, O. L. (2015). Biodiversity and resilience of ecosystem functions. Trends in Ecology \& Evolution, 30(11), 673-684.

Pecuchet, L., Lindegren, M., Hidalgo, M., Delgado, M., Esteban, A., Fock, H. O., ... Payne, M. R. (2017). From traits to life-history strategies: Deconstructing fish community composition across European seas. Global Ecology and Biogeography, 25, 812-822. https://doi.org/10.1111/geb.12587

This article is protected by copyright. All rights reserved. 
Pepin, P. (1991). Effect of temperature and size on development, mortality, and survival rates of the pelagic early life history stages of marine fish. Canadian Journal of Fisheries and Aquatic Sciences, 48(3), 503-518.

Perry, A. L., Low, P. J., Ellis, J. R., \& Reynolds, J. D. (2005). Climate change and distribution shifts in marine fishes. Science, 308(5730), 1912-1915.

Petereit, C., Hinrichsen, H.-H., Voss, R., Kraus, G., Freese, M., \& Clemmesen, C. (2009). The influence of different salinity conditions on egg buoyancy and development and yolk sac larval survival and morphometric traits of Baltic Sea sprat (Sprattus sprattus balticus Schneider). Scientia Marina, 73(S1), 59-72.

Pillar, V. D., Blanco, C. C., Müller, S. C., Sosinski, E. E., Joner, F., \& Duarte, L. D. S. (2013). Trait redundancy and stability in plant communities. Journal of Vegetation Science, 24(5), 963-974. https://doi.org/10.1111/jvs.12047

Pratchett, M. S., Munday, P., Wilson, S. K., Graham, N., Cinner, J. E., Bellwood, D. R., ... McClanahan, T. (2008). Effects of climate-induced coral bleaching on coral-reef fishes. Ecological and Economic Consequences. Oceanography and Marine Biology: An Annual Review, 46, 251-296.

Richardson, L. E., Graham, N. A. J., Pratchett, M. S., \& Hoey, A. S. (2017). Structural complexity mediates trait structure of reef fish assemblages among coral habitats. Environmental Biology of Fishes, 100(3), 193-207. https://doi.org/10.1007/s10641016-0571-0

Richardson, L. E., Graham, N. A., Pratchett, M. S., Eurich, J. G., \& Hoey, A. S. (2018). Mass coral bleaching causes biotic homogenization of reef fish assemblages. Global Change Biology, 24, 3117-3129. https://doi.org/10.1111/gcb.14119

This article is protected by copyright. All rights reserved. 
Ricotta, C., de Bello, F., Moretti, M., Caccianiga, M., Cerabolini, B. E. L., \& Pavoine, S. (2016). Measuring the trait redundancy of biological communities: a quantitative guide. Methods in Ecology and Evolution, 7(11), 1386-1395. https://doi.org/10.1111/2041-210X.12604

Rijnsdorp, A. D., Peck, M. A., Engelhard, G. H., Möllmann, C., \& Pinnegar, J. K. (2009). Resolving the effect of climate change on fish populations. ICES Journal of Marine Science, 66(7), 1570-1583. https://doi.org/10.1093/icesjms/fsp056

Rogers, A., Blanchard, J. L., \& Mumby, P. J. (2014). Vulnerability of coral reef fisheries to a loss of structural complexity. Current Biology, 24(9), 1000-1005.

Rosenfeld, J. S. (2002). Trait redundancy in ecology and conservation. Oikos, 98(1), 156162. https://doi.org/10.1034/j.1600-0706.2002.980116.x

Sakschewski, B., von Bloh, W., Boit, A., Poorter, L., Peña-Claros, M., Heinke, J., ... Thonicke, K. (2016). Resilience of Amazon forests emerges from plant trait diversity. Nature Climate Change, 6(11), 1032-1036. https://doi.org/10.1038/nclimate3109

Sanders, D., Thébault, E., Kehoe, R., \& van Veen, F. F. (2018). Trophic redundancy reduces vulnerability to extinction cascades. Proceedings of the National Academy of Sciences, 115(10), 2419-2424.

Saulquin, B., \& Gohin, F. (2010). Mean seasonal cycle and evolution of the sea surface temperature from satellite and in situ data in the English Channel for the period 19862006. International Journal of Remote Sensing, 31(15), 4069-4093. https://doi.org/10.1080/01431160903199155

Schneider, F. D., Brose, U., Rall, B. C., \& Guill, C. (2016). Animal diversity and ecosystem functioning in dynamic food webs. Nature Communications, 7, 12718. https://doi.org/10.1038/ncomms12718 
Segan, D. B., Murray, K. A., \& Watson, J. E. M. (2016). A global assessment of current and future biodiversity vulnerability to habitat loss-climate change interactions. Global Ecology and Conservation, 5, 12-21. https://doi.org/10.1016/j.gecco.2015.11.002

Simpson, S. D., Jennings, S., Johnson, M. P., Blanchard, J. L., Schön, P.-J., Sims, D. W., \& Genner, M. J. (2011). Continental shelf-wide response of a fish assemblage to rapid warming of the sea. Current Biology, 21(18), 1565-1570. https://doi.org/10.1016/j.cub.2011.08.016

Sirot, C., Villéger, S., Mouillot, D., Darnaude, A., Ramos-Miranda, J., Flores-Hernandez, D., \& Panfili, J. (2015). Combinations of biological attributes predict temporal dynamics of fish species in response to environmental changes. Ecological Indicators, 48, 147156.

Skogen, M. D., Svendsen, E., Berntsen, J., Aksnes, D., \& Ulvestad, K. B. (1995). Modelling the primary production in the North Sea using a coupled three-dimensional physicalchemical-biological ocean model. Estuarine, Coastal and Shelf Science, 41(5), 545565.

Smith, M. R., \& Myers, S. S. (2018). Impact of anthropogenic CO2 emissions on global human nutrition. Nature Climate Change, 8(9), 834-839. https://doi.org/10.1038/s41558-018-0253-3

Spasojevic, M.J., \& Suding, K.N. (2012). Inferring community assembly mechanisms from trait diversity patterns: the importance of multiple assembly processes. Journal of Ecology, 100(3), 652-661. https://doi.org/10.1111/j.1365-2745.2011.01945.x

Stuart-Smith, R. D., Bates, A. E., Lefcheck, J. S., Duffy, J. E., Baker, S. C., Thomson, R. J., ... Edgar, G. J. (2013). Integrating abundance and functional traits reveals new global hotspots of fish diversity. Nature, 501(7468), 539-542. https://doi.org/10.1038/nature12529 
Sundby, S., \& Kristiansen, T. (2015). The Principles of Buoyancy in Marine Fish Eggs and Their Vertical Distributions across the World Oceans. PLOS ONE, 10(10), e0138821. https://doi.org/10.1371/journal.pone.0138821

Thackeray, S. J., Henrys, P. A., Hemming, D., Bell, J. R., Botham, M. S., Burthe, S., ... Wanless, S. (2016). Phenological sensitivity to climate across taxa and trophic levels. Nature, 535, 241.

Thorson, J. T., Munch, S. B., Cope, J. M., \& Gao, J. (2017). Predicting life history parameters for all fishes worldwide. Ecological Applications, 27(8), 2262-2276. https://doi.org/10.1002/eap.1606

Ting, M., Kushnir, Y., Seager, R., \& Li, C. (2009). Forced and internal twentieth-century SST trends in the North Atlantic. Journal of Climate, 22(6), 1469-1481.

Van den Brink, P. J., Hattink, J., Bransen, F., Van Donk, E., \& Brock, T. C. M. (2000). Impact of the fungicide carbendazim in freshwater microcosms. II. Zooplankton, primary producers $\quad$ and final conclusions. Aquatic Toxicology, 48(2), 251-264. https://doi.org/10.1016/S0166-445X(99)00037-5

Villéger, S., Brosse, S., Mouchet, M., Mouillot, D., \& Vanni, M. J. (2017). Functional ecology of fish: current approaches and future challenges. Aquatic Sciences, 1-19.

Villéger, S., Mason, N. W., \& Mouillot, D. (2008). New multidimensional trait diversity indices for a multifaceted framework in functional ecology. Ecology, 89(8), 22902301.

Villéger, S., Miranda, J. R., Hernández, D. F., \& Mouillot, D. (2010). Contrasting changes in taxonomic vs. trait diversity of tropical fish communities after habitat degradation. Ecological Applications, 20(6), 1512-1522.

Violle, C., \& Jiang, L. (2009). Towards a trait-based quantification of species niche. Journal of Plant Ecology, 2(2), 87-93. https://doi.org/10.1093/jpe/rtp007 
Violle, C., Navas, M.-L., Vile, D., Kazakou, E., Fortunel, C., Hummel, I., \& Garnier, E. (2007). Let the concept of trait be functional! Oikos, 116(5), 882-892. https://doi.org/10.1111/j.0030-1299.2007.15559.x

Walker, B. H. (1992). Biodiversity and Ecological Redundancy. Conservation Biology, 6(1), $18-23$.

Williams, N. M., Crone, E. E., Roulston, T. H., Minckley, R. L., Packer, L., \& Potts, S. G. (2010). Ecological and life-history traits predict bee species responses to environmental disturbances. Biological Conservation, 143(10), 2280-2291. https://doi.org/10.1016/j.biocon.2010.03.024

Wilson, S., Graham, N., \& Polunin, N. (2007). Appraisal of visual assessments of habitat complexity and benthic composition on coral reefs. Marine Biology, 151(3), 10691076.

Wilson S. K., Fisher R., Pratchett M. S., Graham N. A. J., Dulvy N. K., Turner R. A., ... Rushton S. P. (2008). Exploitation and habitat degradation as agents of change within coral reef fish communities. Global Change Biology, 14(12), 2796-2809. https://doi.org/10.1111/j.1365-2486.2008.01696.x

Wittebolle, L., Marzorati, M., Clement, L., Balloi, A., Daffonchio, D., Heylen, K., ... Boon, N. (2009). Initial community evenness favours functionality under selective stress. Nature, 458, 623.

Wohl, D. L., Arora, S., \& Gladstone, J. R. (2004). Trait redundancy supports biodiversity and ecosystem function in a closed and constant environment. Ecology, 85(6), 1534-1540. https://doi.org/10.1890/03-3050

Yachi, S., \& Loreau, M. (1999). Biodiversity and ecosystem productivity in a fluctuating environment: the insurance hypothesis. Proceedings of the National Academy of Sciences of the United States of America, 96(4), 1463-1468.

This article is protected by copyright. All rights reserved. 


\section{Tables}

TABLE 1 Results of Generalized Linear Models using Akaike weights to assess and rank the importance of independent variables in determining sensitivity. Akaike weight means and standard deviations were derived across all models (full model of 7 traits and all combinations of 6 out of 7 traits).

\begin{tabular}{llll}
\hline \multicolumn{2}{c}{ Eastern English Channel } & \multicolumn{2}{c}{ Seychelles Islands } \\
\hline Factors & $\begin{array}{c}\text { AIC Weight } \\
\text { Mean } \pm \text { SD }\end{array}$ & Factors & $\begin{array}{l}\text { AIC Weight } \\
\text { Mean } \pm \text { SD }\end{array}$ \\
& $0.99 \pm 0.01$ & Initial PCoA 1 position & $0.56 \pm 0.21$ \\
Trait redundancy & $0.98 \pm 0.03$ & Trait redundancy & $0.44 \pm 0.21$ \\
Initial PCoA 2 position & $0.84 \pm 0.13$ & $\Delta$ Coral cover (\%) & $0.33 \pm 0.12$ \\
$\Delta$ Salinity & $0.40 \pm 0.10$ & Depth & $0.32 \pm 0.10$ \\
$\Delta$ Sea surface temperature & $0.36 \pm 0.07$ & Initial PCoA 2 position & $0.24 \pm 0.14$ \\
Depth & $0.28 \pm 0.07$ & Species richness & $0.21 \pm 0.04$ \\
Initial PCoA 1 position & $0.24 \pm 0.01$ & $\Delta$ Reef complexity $(\%)$ & $0.19 \pm 0.06$ \\
Species richness & & Management status & $0.18 \pm 0.02$ \\
\hline
\end{tabular}

This article is protected by copyright. All rights reserved. 


\section{Figure Captions}

FIGURE 1 Conceptual diagrams showing the calculation of sensitivity according to changes in the abundance-weighted community position in trait space (a) following disturbance (b), along with potential links between i) sensitivity and initial trait structure (c) and ii) sensitivity and initial trait redundancy (TRed) (d). In (a) black circles represent species positions' in trait space with sizes scaled by abundance and the white circle represents the abundance-weighted community centroid. Panel (b) shows sensitivity calculated as the distance moved in trait space following a disturbance. In (c) communities in the upper area of trait space have sensitive trait structures and exhibit large shifts (arrows), whereas communities in the lower area have resistant trait structures. In (d) communities with low trait redundancy exhibit large shifts (arrows), indicating high sensitivity, whereas communities with high trait redundancy exhibit resistance.

FIGURE 2 Trait space and sensitivity of fish communities in the Eastern English Channel (EEC) and Seychelles Islands. a) Trait structure of the overall EEC fish community. b) Sensitivity of fish communities in the EEC defined by the distance moved (i.e., amount of change) in trait space following disturbance; larger circles $=$ higher movement and therefore higher sensitivity. c) Trait structure of the overall Seychelles fish community. d) Sensitivity of fish communities in the Seychelles defined by the distance moved in trait space following disturbance.

FIGURE 3 Partial relationships from Generalized Linear Models (GLMs) between sensitivity and the most important explanatory factors in the Eastern English Channel (EEC) and Seychelles Islands. Relationships between sensitivity and i) initial position on PCoA axis 2 of trait space (a), ii) initial trait redundancy (b), and iii) local salinity changes (c) in the EEC. Relationships between sensitivity and i) initial position on PCoA axis 1 of trait space (d), ii) initial trait redundancy (e), and iii) coral cover change (f) in the Seychelles. Relationships were plotted using the inverse link function from GLMs via the R package Visreg.

FIGURE 4 Results of null models comparing the observed slopes of the relationships between sensitivity and i) initial PCoA 2 position, and ii) initial trait redundancy in the Eastern English Channel (a, b) and between sensitivity and i) initial PCoA 1 position, and ii) initial trait redundancy in the Seychelles Islands (c, d). Solid black lines indicate the mean slope of the null models, while dashed lines and dotted lines indicate the $95^{\text {th }}$ and $99^{\text {th }}$ percentiles of the null models, respectively.

FIGURE 5 Relationship between trait redundancy and sensitivity in two fish communities from the Eastern English Channel (chosen to highlight low and high redundancy examples). In panels a and c, circles represent species, and circle sizes are scaled by initial (i.e., pre- 
disturbance) abundances. In panels $b$ and $d$, circle sizes are scaled by species' abundance changes and colors indicate whether abundances increased or decreased. The community with low trait redundancy $(\mathrm{a}, \mathrm{b})$ had only one dominant species supporting the pelagic ecological role (bottom-right corner), while the community with high trait redundancy (c, d) had multiple abundant species supporting the pelagic role. Both sites suffered major declines in one pelagic species and minor increases in demersal species (b, d). However the site with low trait redundancy underwent a major shift from pelagic to demersal community structure (b), whereas the site with high trait redundancy was resistant to change (d), as the remaining abundant pelagic fishes maintained the ecological role.

This article is protected by copyright. All rights reserved. 
(a)

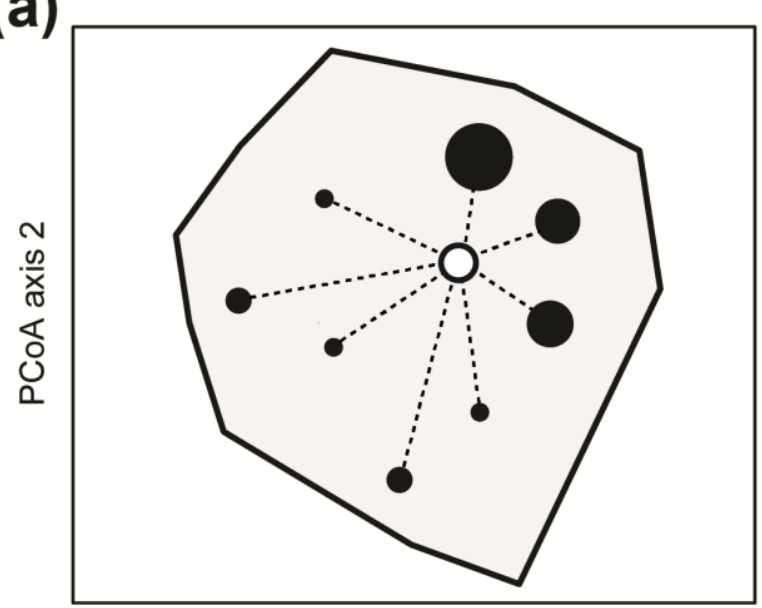

PCoA axis 1

(c)

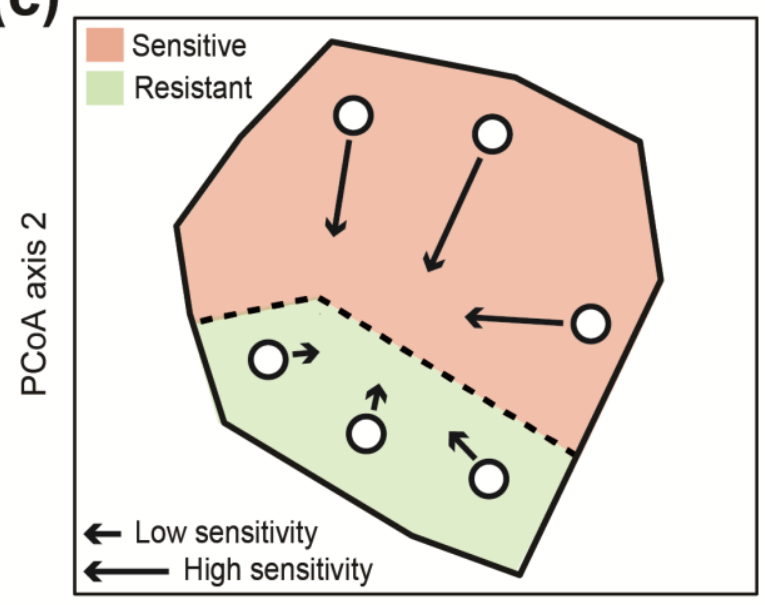

PCoA axis 1

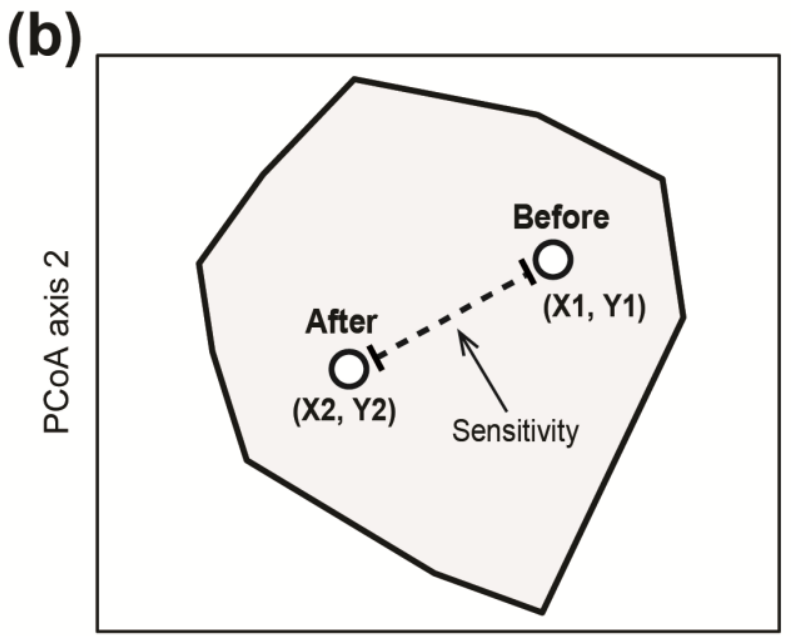

PCoA axis 1

(d)

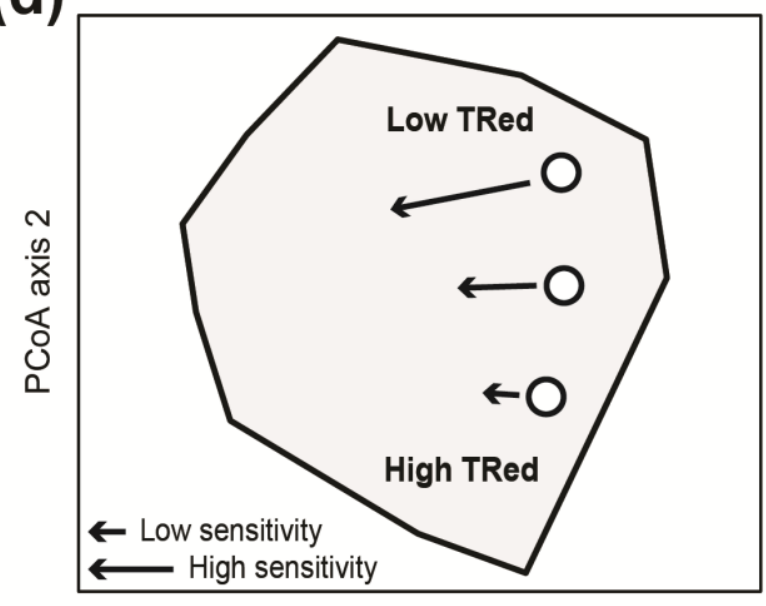

PCoA axis 1 


\section{Eastern English Channel}

(a)

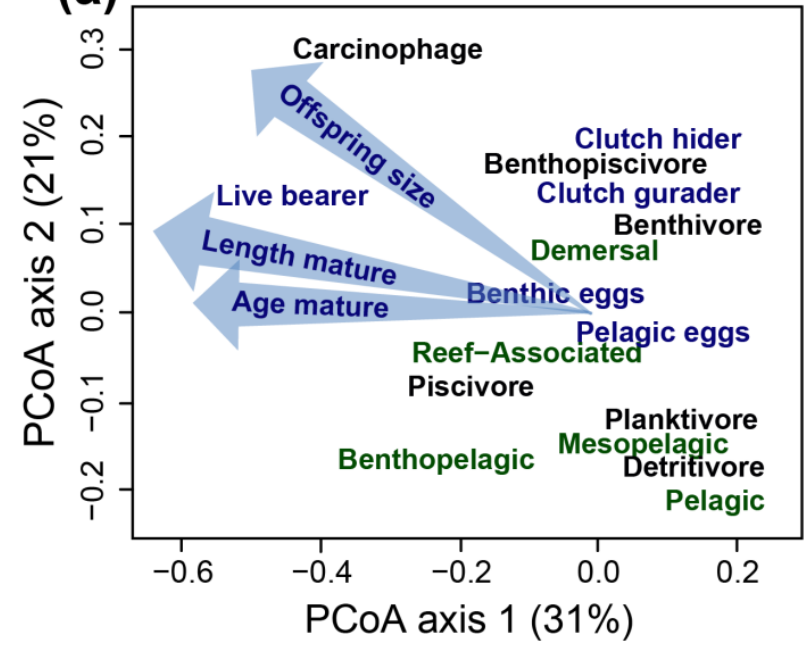

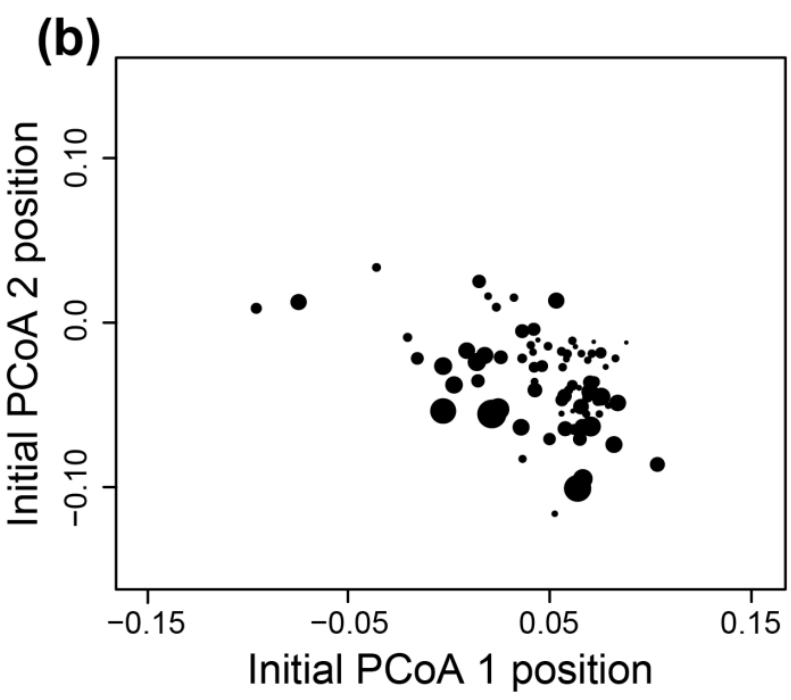

\section{Seychelles Islands}
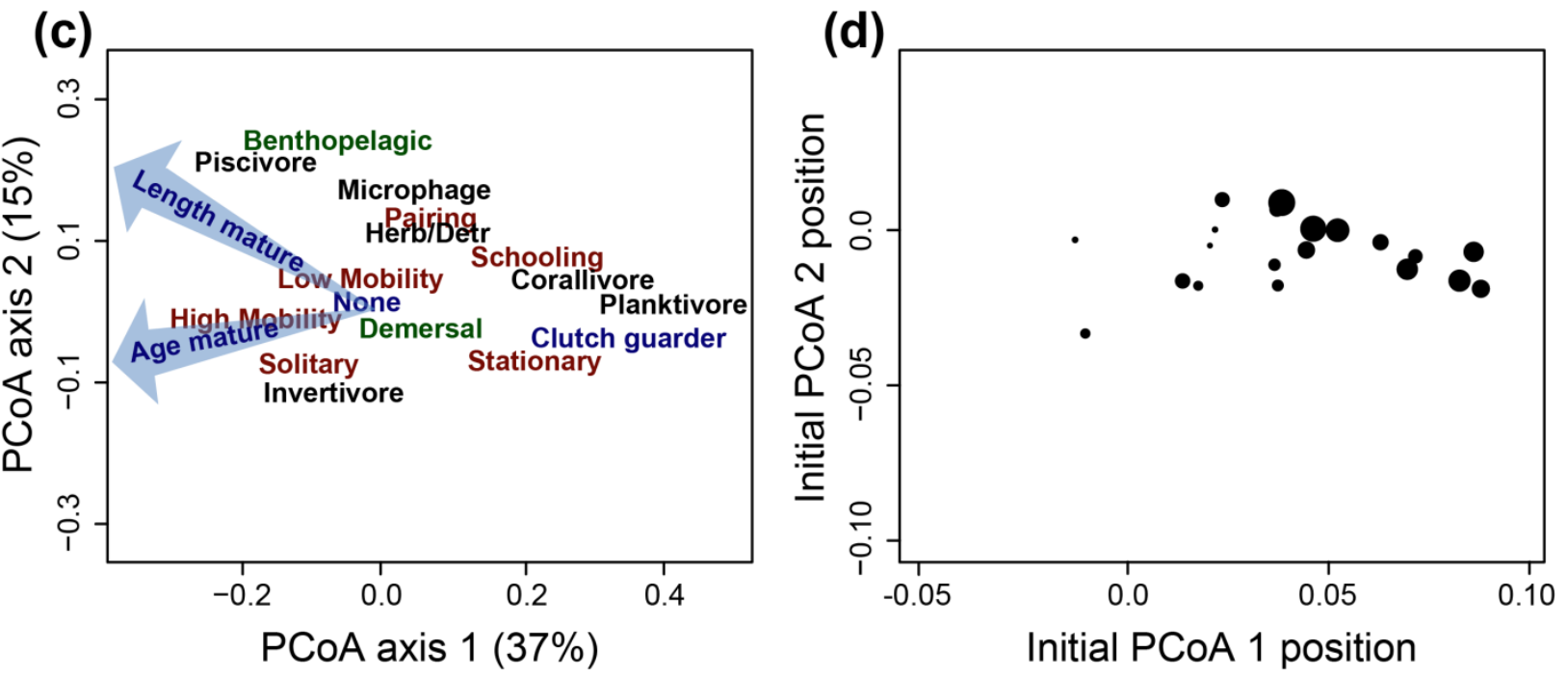

This article is protected by copyright. All rights reserved. 


\section{Eastern English Channel}
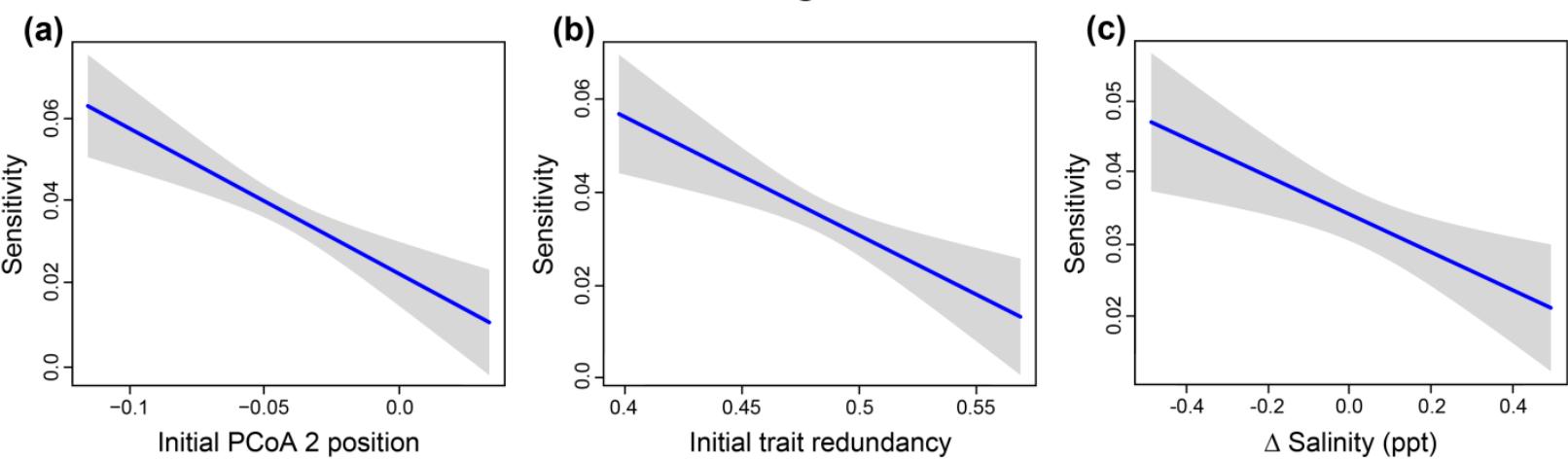

\section{Seychelles Islands}
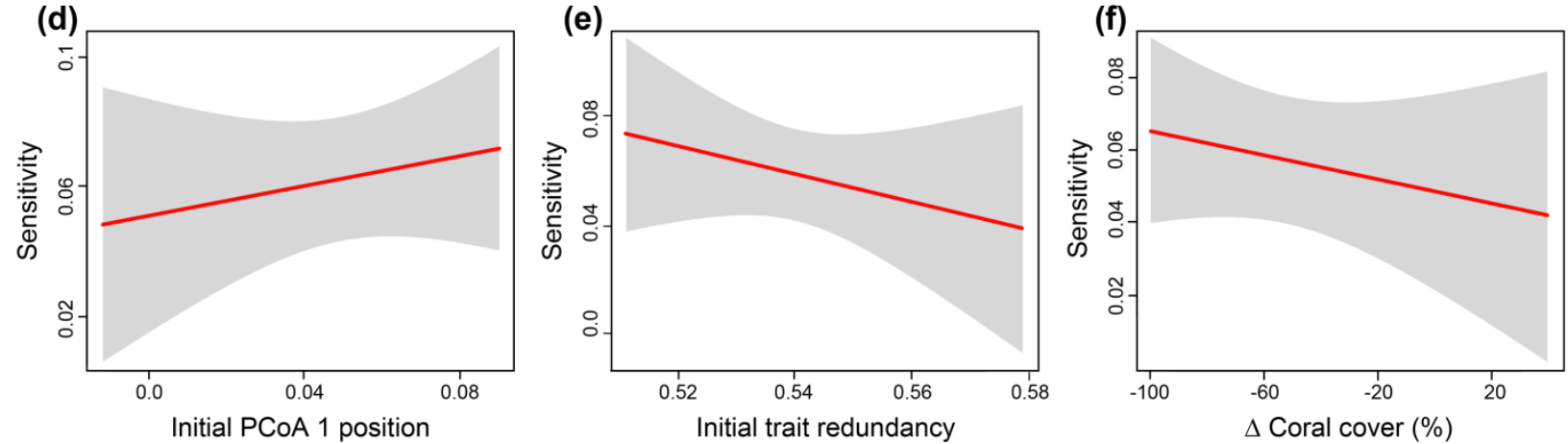

This article is protected by copyright. All rights reserved. 


\section{Eastern English Channel}

(a)

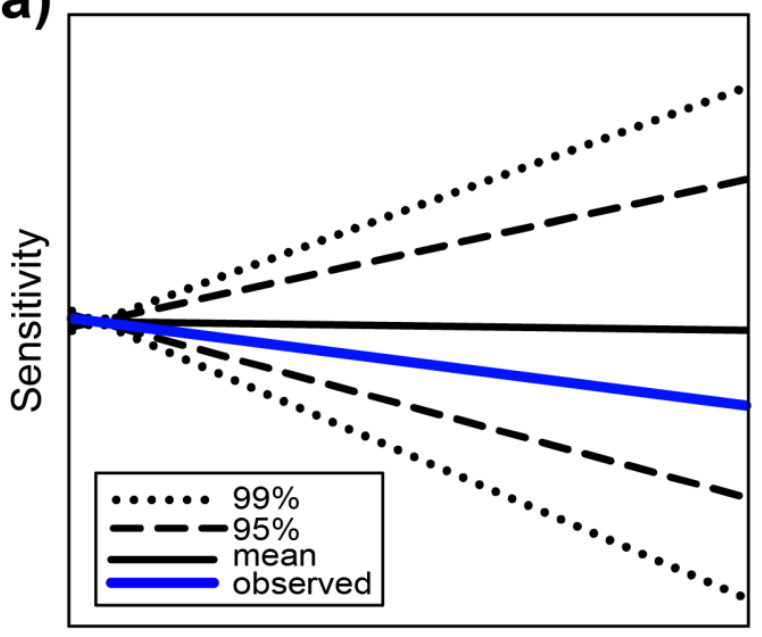

Initial position on PCOA 2 (b)

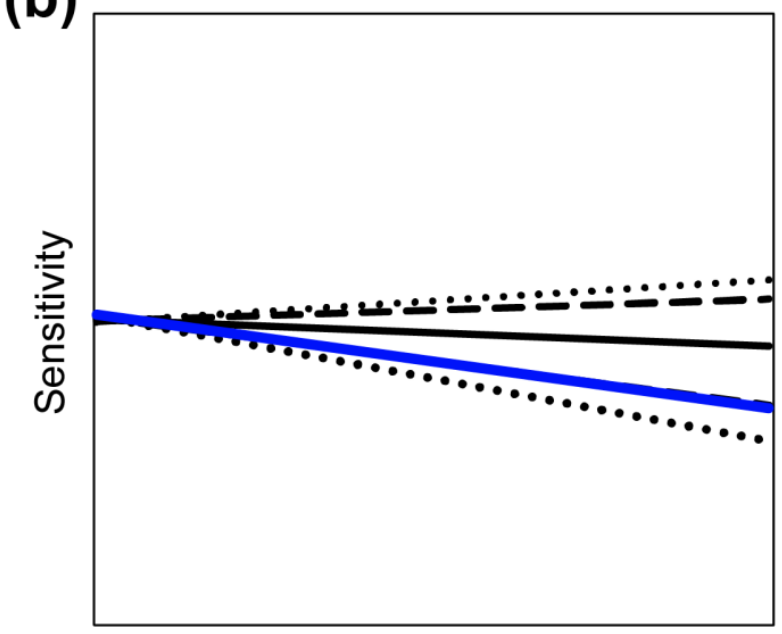

Initial trait redundancy

\section{Seychelles Islands}

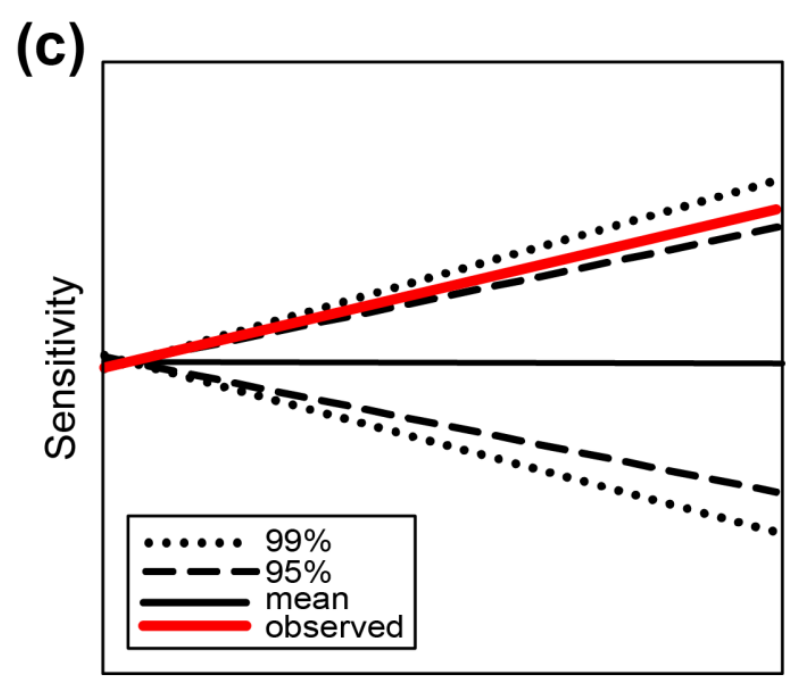

Initial position on PCoA 1 (d)

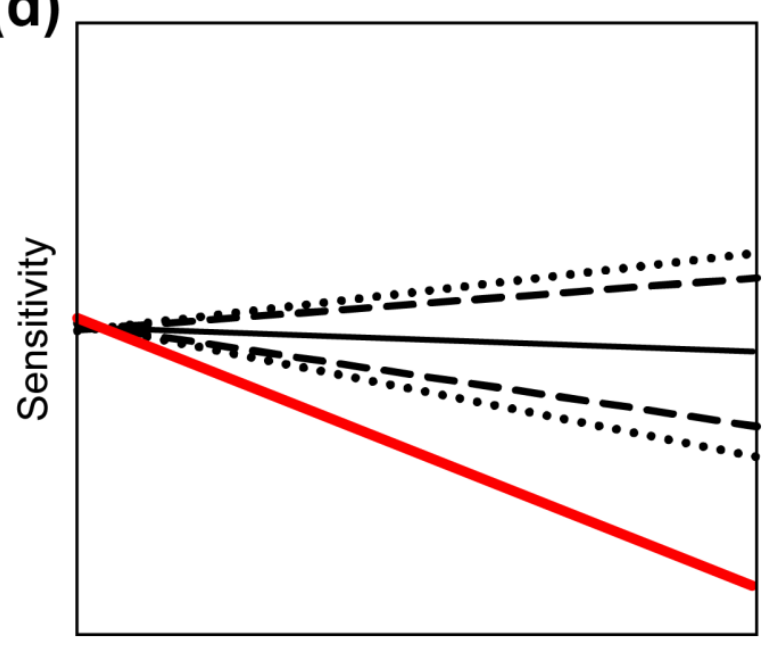

Initial trait redundancy 


\section{Low Redundancy}
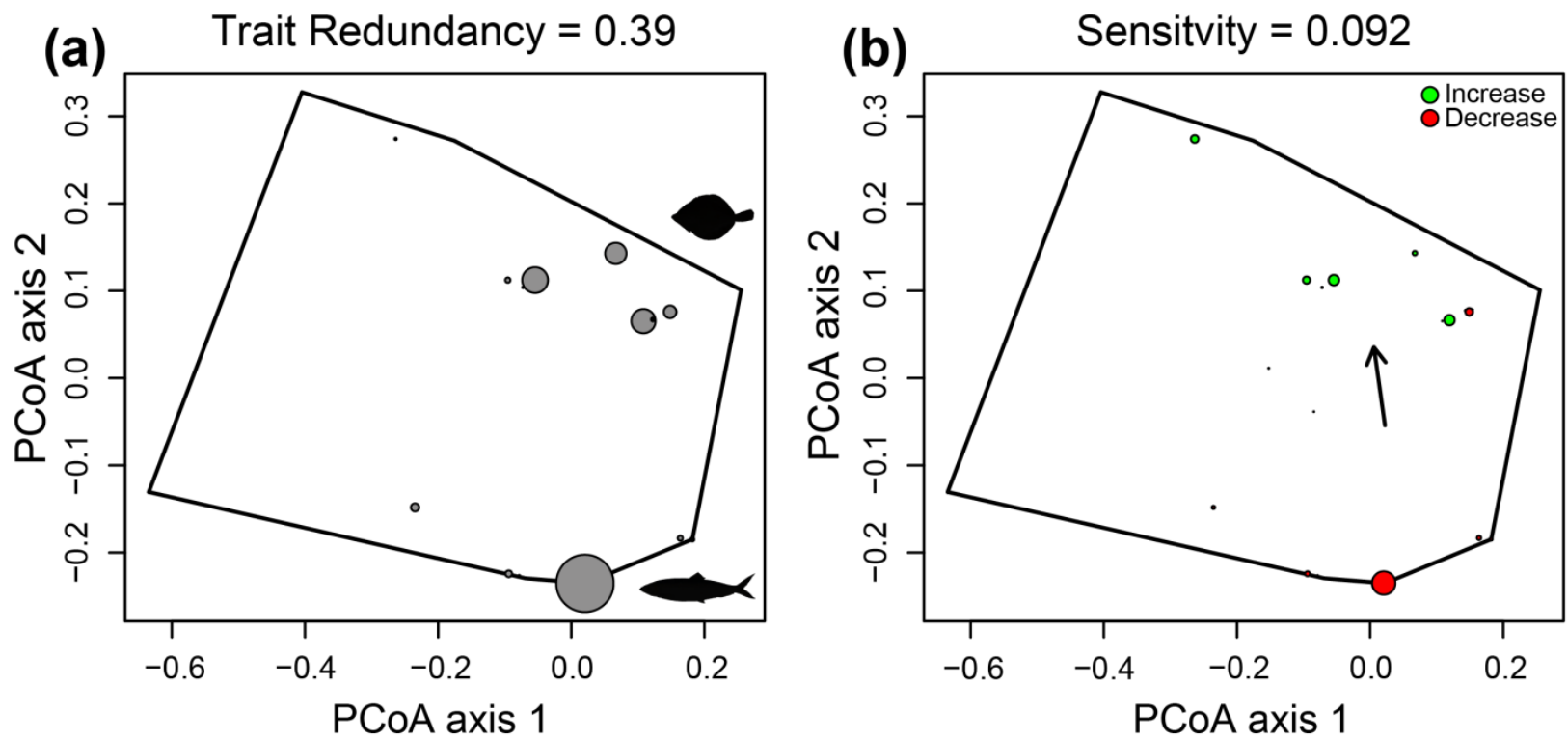

High Redundancy
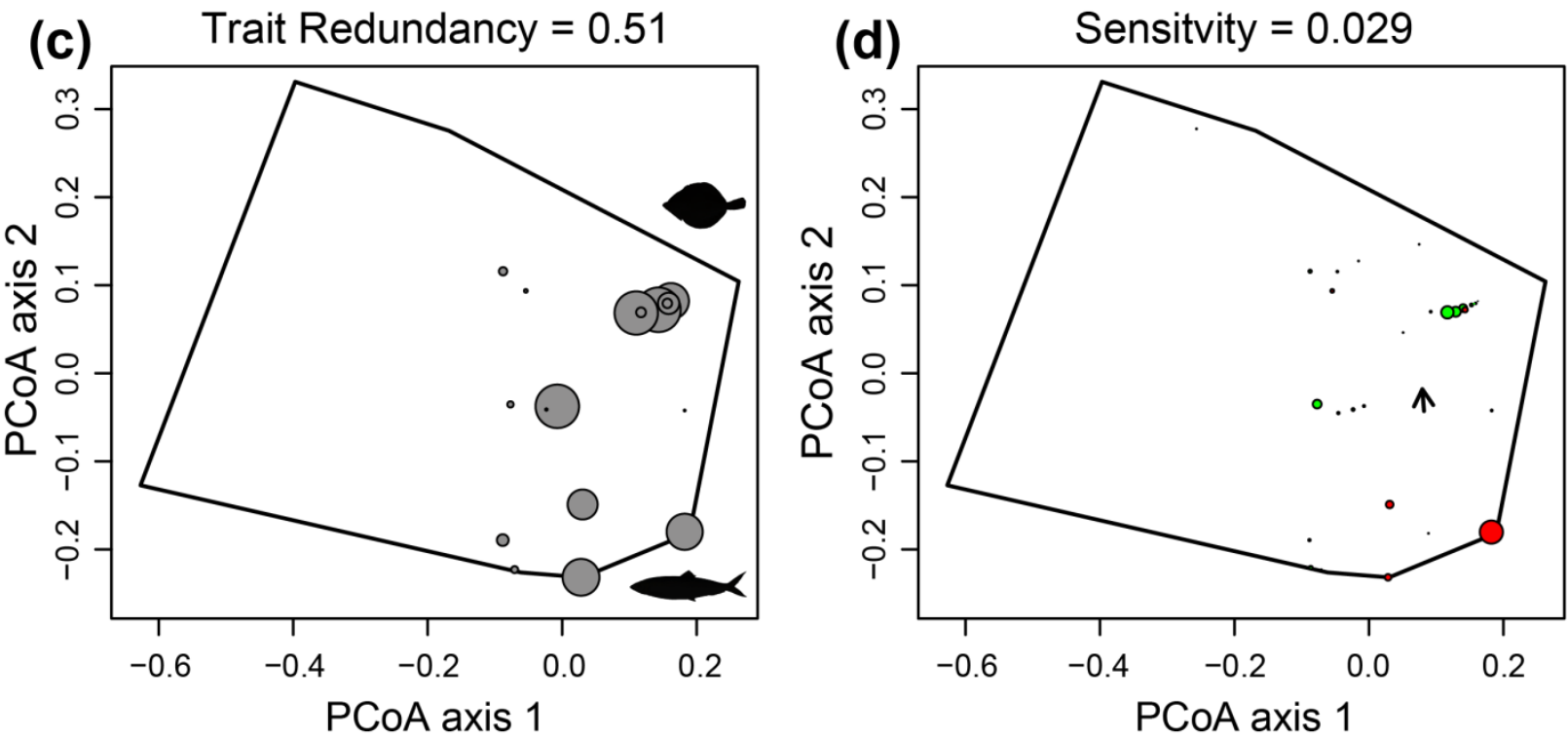